\title{
Development and Validation of a Military Training Mental Toughness Inventory
}

Arthur, C.A.; Fitzwater, J.; Hardy, L.J.; Beattie, S.J.; Bell, J.

\section{Military Psychology}

DOI:

$10.1037 / \mathrm{mil} 0000074$

Published: 08/06/2015

Peer reviewed version

Cyswllt i'r cyhoeddiad / Link to publication

Dyfyniad o'r fersiwn a gyhoeddwyd / Citation for published version (APA):

Arthur, C. A., Fitzwater, J., Hardy, L. J., Beattie, S. J., \& Bell, J. (2015). Development and Validation of a Military Training Mental Toughness Inventory. Military Psychology, 27(4), 232241. https://doi.org/10.1037/mil0000074

\section{Hawliau Cyffredinol / General rights}

Copyright and moral rights for the publications made accessible in the public portal are retained by the authors and/or other copyright owners and it is a condition of accessing publications that users recognise and abide by the legal requirements associated with these rights. study or research.

- Users may download and print one copy of any publication from the public portal for the purpose of private

- You may not further distribute the material or use it for any profit-making activity or commercial gain

- You may freely distribute the URL identifying the publication in the public portal ?

Take down policy

Publisher allows this work to be made available in this repository. Published by American Psychological Association with the following policy: Authors of articles published in APA journals may post a copy of the final manuscript, as accepted for publication, as a word processing file, on their personal website, their employer's server, or in their institution's repository after it is accepted for publication.

\section{Take down policy}

If you believe that this document breaches copyright please contact us providing details, and we will remove access to the work immediately and investigate your claim. 
Running head: MILITARY TRAINING MENTAL TOUGHNESS INVENTORY

1

2

3

4

5

Development and Validation of a Military Training Mental Toughness Inventory

6

7

8

9

10 Word Count. 5071

11

12

Arthur CA, Fitzwater J, Hardy L, Beattie SJ \& Bell J (2015) Development and validation of a military

13

training mental toughness inventory (Forthcoming), Military Psychology, published by American

14

Psychological Association. @2015 American Psychological Association

15

This article may not exactly replicate the final version published in the APA journal. It is not the copy of record.

16

17

18

19 
MILITARY TRAINING MENTAL TOUGHNESS INVENTORY

\section{Abstract}

24

Three studies were conducted in order to develop and validate a mental toughness instrument

25 for use in military training environments. Study $1(n=435)$ focused on item generation and

26 testing the structural integrity of the Military Training Mental Toughness Inventory

27 (MTMTI). The measure assessed ability to maintain optimal performance under pressure from a range of different stressors experienced by recruits during infantry basic training. Study $2(n=104)$ examined the concurrent validity, predictive validity, and test-retest reliability of the measure. Study $3(n=106)$ confirmed the predictive validity of the measure with a sample of more specialized infantry recruits. Overall, the military training mental toughness inventory demonstrated sound psychometric properties and structural validity. Furthermore, it was found to possess good test-retest reliability, concurrent validity, and predicted performance in two different training contexts with two separate samples. 
MILITARY TRAINING MENTAL TOUGHNESS INVENTORY

46

47

48

49

50

51

52

53

54

Mental toughness has been identified by coaches and athletes as one of the most crucial attributes underpinning performance excellence (e.g., Connaughton, Wadey, Hanton, \& Jones, 2008; Coulter, Mallet, \& Gucciardi, 2010; Jones, Hanton, \& Connaughton, 2002). Indeed, Gould, Hodge, Peterson, and Petlichkoff (1993) reported that 82\% of coaches cited mental toughness as the most important psychological attribute which determined success in wrestling. The research literature on mental toughness has been dominated by qualitative approaches which have significantly shaped our understanding of mental toughness (e.g., Bull, Shambrook, James, \& Brooks, 2005; Connaughton et al., 2008; Coulter et al., 2010; Gucciardi Gordon, \& Dimmock, 2009a; Jones et al., 2002). However, some researchers have argued that qualitative methods have become overused (e.g., Andersen, 2011), while others have urged researchers to develop reliable and valid measures of mental toughness (e.g., Sheard, Golby, \& van Wersch, 2009). Further, Hardy, Bell and Beattie, (2013) argue that one of the limitations of adopting qualitative methods is that researchers are unable to differentiate between the causes of mental toughness, processes, outcomes, and other behaviors that are more likely to be correlates associated with mental toughness.

There are however some notable exceptions to the qualitative approaches, with several quantitatively derived mental toughness measures having been developed (e.g., the Mental Toughness Inventory (MTI; Middleton, Marsh, Martin, Richards, \& Perry, 2004; 2005); the Sport Mental Toughness Questionnaire (SMTQ; Sheard et al., 2009); the Mental Toughness Questionnaire -48 (MTQ-48; Clough, Earl, \& Sewell, 2002); the Cricket Mental Toughness Inventory (CMTI; Gucciardi \& Gordon, 2009). Whilst these various measures of mental toughness have significantly contributed to the mental toughness literature and have gone some way to alleviating the over reliance on qualitative approaches, they are not without their critics (see for example, Gucciardi, Hanton, \& Mallet, 2012). Hardy et al. 
MILITARY TRAINING MENTAL TOUGHNESS INVENTORY

71 (2013) argued that whilst the above measures capture a wide array of values, attitudes,

cognitions and affect, they do not explicitly capture mentally tough behavior. They further argue that psychological variables may influence mental toughness, or be correlates of it, but that the primary focus of such measures should be on assessing the presence or absence of mentally tough behavior. Hardy and colleagues also argue that the use of self-report measures in assessing behaviors may be questionable due to social desirability and self-presentation confounds. To this end, Hardy et al. (2013) developed an informant rated behavior based Mental Toughness Inventory (MTI) in an elite sport context that was underpinned by the following definition, "the ability to achieve personal goals in the face of pressure from a wide range of different stressors" (p. 5). This definition of mental toughness was used to underpin the current research.

It is important to note that researchers into the concept of mental toughness are not alone in attempting to solve the dilemma of ameliorating the potential harmful effects of exposure to stress. Several similar, yet subtly different constructs associated with stress exposure have been proposed, defined and operationalized. These include the concepts of hardiness, resilience, and grit. Hardiness is viewed as a relatively stable personality characteristic, which involves courage, adaptability and the ability to maintain optimal performance under exposure to stress. It has been conceptualized as a combination of three attitudes; commitment, control, and challenge, which provide an individual with existential courage and motivation to appraise stressful situations as opportunities for growth (Kobasa, 1979; Maddi, 2006; 2007). Hardiness and its core components of, commitment, control and challenge are viewed as fundamental to another similar concept, resilience (Maddi, 2007). Resilience is characterized by the ability to recover from negative emotional experiences and the ability to adapt to stressful situations. Another similar psychological construct proposed by Duckworth, Peterson, and Mathews (2007) which involves striving toward challenges and 
MILITARY TRAINING MENTAL TOUGHNESS INVENTORY

maintaining effort and persistence despite adversity, setbacks and failure is termed 'grit,' .

They define grit as, "perseverance and passion for long-term goals" (Duckworth et al., 2007, p. 1087), with the emphasis on long-term stamina, rather than short-term intensity. Kelly et al. (2014) suggest that the concept of grit has obvious utility in the military domain in that it is synonymous with fortitude or courage and the essence of officer cadet development in military academies. Whilst all these psychological concepts describe psychological characteristics that are undoubtedly important in a military context, they differ from the current construct of mental toughness in that, the current research is specifically examining mentally tough 'behavior'. That is, the ability to maintain goal focus and high levels of performance in the face of different stressors. The concepts of hardiness, resilience and grit are described as a constellation of personality characteristics and are as such typically measured at this level. However, mental toughness in the current research is measured and conceptualized at the behavioral level. That is, whilst the behaviors will be to some extent underpinned by personality, the level of measurement is not personality per se. This is an important distinction that will help to further the mental toughness literature by offering a means by which the personality and behavior relationship can be examined. Indeed, Hardy et al. (2013) demonstrated that the current definition of mental toughness was underpinned by Gray \& McNaughton's (2000) revised Reward Sensitivity Theory (rRST).

Hardy et al.'s. (2013) MTI has been shown to have good psychometric properties, strong test-retest reliability and successfully discriminate between professional and nonprofessional athletes. A particular strength of the MTI (which sets it apart from other conceptualizations of mental toughness), is that it was conceptualized within a neuropsychological theoretically driven framework, namely Gray \& McNaughton's (2000) revised Reward Sensitivity Theory (rRST). rRST was used as it has the potential to offer a neuropsychological explanation of the maintenance of goal directed behavior in the face of 
MILITARY TRAINING MENTAL TOUGHNESS INVENTORY

stressful stimuli. Hardy et al. were successful in examining the prediction of mental toughness from rRST personality traits. In a further study, the MTI was used to evaluate the efficacy of a successful mental toughness training intervention (Bell, Hardy \& Beattie, 2013) that was underpinned by Hardy et al.'s findings.

The MTI and the use of rRST (Gray \& McNaughton, 2000) appears to offer some promise in furthering our understanding of mentally tough behavior in elite sport.

Consequently, based on Hardy et al.'s findings, there is a need to develop contextually relevant measures of mentally tough behaviors for other settings. One particular context where mental toughness is undoubtedly important is within the military. However, to date there appears to have been little or no empirical research conducted on mental toughness in the military domain, although there is evidence to suggest that it has recently started to be explored (e.g., Hammermeister, Pickering, \& Lennox, 2011).

Military action requires soldiers to perform under intense pressure in highly stressful environments, characterized by fear, fatigue, and anxiety largely caused by risk to one's life. Typical combat stressors include, for example: exposure to enemy fire and improvised explosive devices, armed combat, and seeing colleagues killed or seriously injured. To demonstrate this, one soldier recently defined mental toughness as, “...gearing yourself up to go on a patrol in Afghanistan, outside the wire, the day after you lost a member of your squad to a sniper, and you know the sniper is still out there" (Lt Col. Burbelo; cited in Hammermeister et al., 2011, p. 4). The purpose of the present study was to develop a behaviorally based measure of mental toughness in a military training environment based upon Hardy et al.'s (2013) definition and measure. Four independent samples, drawn from general and specialized infantry training platoons from a UK-based Army training establishment were employed in the study.

\section{Study 1: Developing the Measure}


MILITARY TRAINING MENTAL TOUGHNESS INVENTORY

\section{Method}

\section{Stage 1: Item Development}

Item development was underpinned by the behaviorally based approach adopted by Hardy et al. (2013). Environmental stressors were identified by conducting focus groups with recruit instructors and senior military personnel. An item pool representative of typical stressors experienced by recruits in training (e.g., feeling fatigued, being reprimanded, pressure to perform well, etc.) was developed by the authors, which were then presented back to the recruit instructors for further refinement. This resulted in a 15 item pool.

\section{Participants and Procedure}

A total of 279 infantry recruits $\left(M_{\text {age }}=21.45, S D=3.16\right)$ who were between 5 and 24 weeks of training $(M=14.18$ weeks, $S D=7.11)$ were reported on by 41 male infantry recruit instructors who had served for an average of 9.03 years in the Army $(S D=2.35)$ and had spent an average of 11.78 months as an instructor $(S D=5.89)$. In order for the instructors to accurately assess the recruits, a minimum of 5 weeks supervision was set for inclusion criteria $(M=11.73$ weeks, $S D=6.84$ weeks $)$.

Infantry recruit instructors are responsible for training infantry recruits through a 26 week Combat Infantryman's Course (CIC). They are all experienced section corporals who are selected to serve a 24 month tenure at a training establishment before returning to their parent unit. The aim of the CIC is to train infantry recruits to the standards required of an infantry soldier to operate as an effective member of a platoon in extremely hostile environments. Infantry training is therefore designed to be both physically and mentally demanding with the majority of instruction and training taking place outdoors and on field exercises. The consequences of failing to meet the required standards at any point in training result in being reallocated to an earlier point in training with another training platoon. 
MILITARY TRAINING MENTAL TOUGHNESS INVENTORY

After receiving institutional ethical approval, instructors and recruits were verbally solicited to take part in the study, informed of the nature of the study and the inclusion criteria. Confidentiality was assured and once the inclusion criteria were satisfied, informed consent was obtained. The same conditions for recruitment, participation and assurance of confidentiality were applied to all of the studies in this research program.

The instructors were asked to complete the 15 items that were retained from stage 1 for each recruit in their section and asked to rate how well they were able to maintain a high level of personal performance when confronted with different stressful situations in training (example items included "when the conditions are difficult" and "when he has been reprimanded or punished"). Responses were based on a 7-point Likert scale that ranged from 1 (never) to 7 (always), with a midpoint anchor of 4 (sometimes).

\section{Results}

Confirmatory factor analysis (CFA) using LISREL 8.80 (Jöreskog \& Sörbom, 2006) was used in an exploratory way to refine the item pool. The fit statistics for the 15 item model was poor $\left(\chi^{2}(90)=511.23, p<0.01\right.$, RMSEA $=.10, \mathrm{CFI}=.97, \mathrm{NFI}=.96, \mathrm{SRMR}=$ .06 , GFI $=.80$ ). Post-hoc item refinement was conducted using the standardized residuals, modification indices for theta delta and theoretical rationale. This process identified a number of items that had considerable conceptual overlap with other items, were ambiguously worded, or referred to environmental conditions that may not be a universal stressor. Removal of these items resulted in a six item scale that demonstrated a good fit to the data $\left(\chi^{2}(9)=17.95, p=.04 ; \mathrm{CFI}=.99, \mathrm{RMSEA}=.03, \mathrm{SRMR}=.02, \mathrm{NFI}=.99, \mathrm{NNFI}=\right.$ .99 , GFI $=.98)$. The mean mental toughness score was $4.17(S D=1.30)$ with an internal consistency (Cronbach's alpha) of .89. Factor loadings ranged from .72 to .81 (see Table 1 for items and descriptives).

\section{Stage 2: Structural Validity}


MILITARY TRAINING MENTAL TOUGHNESS INVENTORY

The purpose of stage 2 was to confirm the factor structure of the MTMTI on a separate sample.

\section{Participants and Procedure}

A total of 156 recruits $\left(M_{\text {age }}=21.33, S D=2.90\right)$ between weeks 7 and 23 of training $(M=14.77$ weeks, $S D=6.49)$ were reported on by 23 instructors $\left(M_{\text {age }}=26.87, S D=2.09\right)$ who had served for an average of 8.48 years in the Army $(S D=2.27)$ and had spent an average of 13.30 months as an instructor $(S D=5.46)$ training recruits. Instructors completed the 6-item MTMTI developed in stage 1.

\section{Results}

CFA revealed that the fit statistics for the six-item model demonstrated an acceptable fit to the data $\left(\chi^{2}(9)=21.89: p<.01 ; \mathrm{CFI}=.99, \mathrm{RMSEA}=.07, \mathrm{SRMR}=.03, \mathrm{NNFI}=.98\right.$, $\mathrm{NFI}=.98)$. The mean mental toughness score was $4.11(S D=1.25)$ with an internal consistency (Cronbach's alpha) of .91. Factor loadings ranged from .72 to .88 .

\section{Method}

\section{Study 2: Test-retest Reliability, Concurrent and Predictive Validity}

\section{Participants}

104 recruits $\left(M_{\text {age }}=22.07, S D=3.92\right)$ took part in Study 2 . They were reported on by 15 different instructors $\left(M_{\text {age }}=26.61, S D=2.12\right)$ who had served for an average of 8.70 years in the Army $(S D=2.08)$ and had spent an average of 12.17 months as an instructor $(S D=$ 5.93). The recruits had been under the supervision of the reporting instructors for an average of 17.95 weeks $(S D=5.83)$.

\section{Instruments}

MTMTI .The MTMTI developed and validated in Study 1 was used.

Concurrent validity of the MTMTI was tested by selecting variables that are theorized to correlate with mentally tough behavior (e.g., self-report mental toughness, self-confidence, 
MILITARY TRAINING MENTAL TOUGHNESS INVENTORY

and resilience measures). Predictive validity was tested by assessing the extent to which the MTMTI predicated performance.

Sport Mental Toughness Inventory. The sport mental toughness questionnaire (SMTQ;

Sheard et al., 2009) is a 14-item measure that consists of three subscales; confidence, constancy and control. These subscales can be combined to create a global measure of mental toughness. The scale is measured on a 4-point Likert scale anchored at 1 (not at all true) to 4 (very true). Example items include, "I have what it takes to perform well under pressure" (confidence); "I am committed to completing the tasks I have to do" (constancy); and, "I worry about performing poorly" (control; reverse scored). CFA has been shown to provide good support for the 3-factor model (Sheard et al., 2009).

Self-Confidence. Self-confidence was measured using a 5-item scale that was developed and validated by Hardy et al. (2010) in a military training context by asking, "compared to the most confident recruit you know, how would you rate your confidence in your ability to.... (e.g., "...meet the challenges of training)". The response format is rated on a 5-point Likert scale anchored at 1 (low) to 5 (high). This scale has been shown to have good psychometric and predictive validity in a military training context (Hardy et al.,).

Resilience Scale. Resilience was measured using a 4-item resilience scale developed specifically for use in a military training context by Hardy et al. (2010). The stem and response format used was the same as the self-confidence scale. Example items include, "... adapt to different situations in training and be successful". This scale has been shown to have good psychometric and predictive validity in a military training context (Hardy et al., 2013).

Performance. Performance was determined by the recruits' end of course final grades, based on their weekly reports and grades throughout the CIC. This grade is awarded by the platoon commander (Lieutenant or Captain) and ranges from 0 (fail) to 6 (excellent). 
MILITARY TRAINING MENTAL TOUGHNESS INVENTORY

\section{Procedure}

To assess test-retest validity, the MTMTI was administered at weeks 20 and 23 of training. The self-report SMTQ, resilience and confidence scales were administered during week 23 of training, and the performance data was collected at the end of training (week 26).

\section{Results}

Descriptive statistics and correlations for all study variables are displayed in Table 2.

The MTMTI demonstrated a good fit to the data $\left(\chi^{2}(9)=6.81, p=.66\right.$; RMSEA $=.00$, NNFI $=1.00, \mathrm{CFI}=1.00, \mathrm{SRMR}=.01)$, although this result should be interpreted with caution due to the small sample size.

\section{Test-Retest Reliability}

The mean mental toughness score at week 20 was $4.95(\mathrm{SD}=1.34)$, and the mean score at week 23 was $4.89(S D=1.36)$. A paired sample t-test revealed that these means were not significantly different $(t(103)=0.63, p=>.05)$. The test-retest reliability for the MTMTI was .72.

\section{Concurrent Validity}

Table 2 demonstrates that the MTMTI significantly correlated with the global SMTQ ( $r$ $=.43$ ), the separate subscales of the SMTQ (confidence $r=.37$, constancy $r=.40$, and control $r=.24)$, and Hardy et al's. (2010) subscales of resilience $(r=.35)$, and confidence ( $r$ $=.33)$.

\section{Predictive Validity}

Regression analysis revealed that mental toughness significantly predicted individual course performance $\left(\mathrm{R}^{2}=.31 ; \beta=.56, p=<.01\right)$. Furthermore, hierarchical regression analyses revealed that the MTMTI accounted for a significant proportion of variance in course performance (Block 2: $\Delta \mathrm{R}^{2}=.19 ; \beta=.48, p<.01$ ) over and above that accounted for by the SMTQ (Block $1: \mathrm{R}^{2}=.15 ; \beta=.19, p<.01$ ). We also tested whether the MTMTI 
MILITARY TRAINING MENTAL TOUGHNESS INVENTORY accounted for variance in performance after controlling for all the self-report variables used in the current study. The results revealed that the MTMTI accounted for a significant proportion of variance in performance (Block 2: $\Delta \mathrm{R}^{2}=.18 ; \beta=.48, p<.01$ ) over and above that accounted for by all the self-report measures (Block $1: \mathrm{R}^{2}=.17, p<.05$ ).

\section{Study 3: Further Test of Predictive Validity}

Study 2 demonstrated the test re-test reliability, concurrent and predictive validity of the MTMTI. Furthermore the MTMTI was shown to predict performance after controlling for self-reported mental toughness. The aim of Study 3 was to further test the predictive validity of the MTMTI in a specialized infantry context, namely the Parachute Regiment (Para).

While initial training for the infantry is necessarily arduous and demanding, initial training for Para recruits is widely regarded by the British Army as being the most physically and mentally demanding of all Infantry regiments in the British Armed Forces (Wilkinson, Rayson, \& Bilzon, 2008). Their specialist role requires them to operate at a higher intensity than the regular infantry, carrying heavy loads for longer distances, at a faster pace as well as withstanding the hardships of operating independently in the field for long periods under harsh environmental conditions (Wilkinson et al., 2008). To determine their suitability for this role, at week 20 of the CIC Para recruits are required to undergo a pre-Para selection testweek (PPS), known colloquially as P-Company. P-Company consists of a series of physically demanding team and individual events that involve carrying personal equipment weighing $20 \mathrm{~kg}$ or more for distances of up to $32 \mathrm{~km}$ over severe terrain with time constraints, a steeplechase assault course and aerial confidence course. Two team events require the participants to run with a $60 \mathrm{~kg} \log$ and $80 \mathrm{~kg}$ stretcher for $2.5 \mathrm{~km}$ and $8 \mathrm{~km}$ respectively. Pass rates typically range between $\sim 40-70 \%$. 
MILITARY TRAINING MENTAL TOUGHNESS INVENTORY

294

295

296

297

298

299

300

301

302

303

304

305

306

307

308

309

310

311

312

313

314

315

316

317

318

Furthermore, the nature of the military performance indicators is such that they tend to be very physical in nature. However, whilst a specific level of fitness is required for military service, the various tests are designed to assess recruits abilities to perform under stressful and arduous conditions. That is, it is not just fitness that determines the quality of a Para recruit but the ability to maintain a high level of performance in stressful and arduous conditions. Success on P-Company entitles a recruit to wear the coveted maroon beret and pass out of training into a Parachute Regiment unit. Conversely, failure results in the recruit being reallocated to a platoon earlier in the training cycle or transfer to another infantry regiment. The recruits have been training for this test week for the preceding 20 weeks. It is hypothesized that fitness will predict performance on P-Company but, more importantly, mental toughness will predict variance in performance on P-Company after controlling for fitness.

\section{Method}

\section{Participants}

Participants for Study 3 were 134 Para recruits $\left(M_{\text {age }}=19.95, S D=4.14\right)$ who were reported on by 20 different Para recruit instructors $\left(M_{\text {age }}=28.71\right.$ years, $\left.S D=2.92\right)$ who had served for an average of 10.65 years in the Army $(S D=2.63)$ and had spent an average of 10.95 months as an instructor $(S D=4.87)$. The recruits had been under the supervision of their respective instructors for between 7 and 20 weeks $(M=15.31$ weeks, $S D=4.06)$.

\section{Instruments}

\section{Mental Toughness}

The MTMTI was used to measure mental toughness. Performance

During P-Company, participants can achieve a maximum of 70 points, determined by their performance on each event (i.e., up to 10 points for each of the 7 events; the aerial 
MILITARY TRAINING MENTAL TOUGHNESS INVENTORY

confidence course is a pass or fail test). Most of the points are awarded objectively based on time to complete or completion of an event and are awarded by P-Company staff who are independent of the recruits' regular training team. Performance scores in the current sample ranged from $10-70(M=49.95, S D=15.07)$.

\section{Fitness}

An objective measure of fitness was used to control for individual fitness. During training, recruits are required to complete physical assessments to measure progression in individual fitness. One of these assessments is a two-mile loaded run in less than 18 minutes, carrying a $16 \mathrm{~kg}$ pack and rifle. Another assessment is a timed run over a steeplechase assault course consisting of several dry and water obstacles. Each event generates an individual time. Two-mile loaded times for this cohort ranged from 15 minutes and 30's to 22 minutes and 47's $(M=18: 39, S D=1: 37)$. The steeplechase times ranged from 18 minutes 30's to 22 minutes 26's $(M=20: 19, S D=1: 08)$. In order to create an overall indication of fitness these times were standardized within event and were then combined to create an overall score. We then multiplied the overall score by -1 so that a higher score was indicative of better performance.

\section{Procedure}

The fitness tests were conducted during week 18 of training and the MTMTI was administered at the end of week 19 of training. P-Company was conducted at week 20 of training.

\section{Results}

Descriptive statistics and correlations for all study variables are displayed in Table 2. Consistent with Studies 1 and 2, the MTMTI demonstrated a good fit to the data $\left(\chi^{2}(9)=\right.$ 14.07, $p=0.12 ; \mathrm{RMSEA}=.06, \mathrm{NNFI}=.99, \mathrm{CFI}=1.00, \mathrm{SRMR}=.03)$. The mean mental 
MILITARY TRAINING MENTAL TOUGHNESS INVENTORY

343

toughness score was $4.94(S D=1.02)$ with an internal consistency (Cronbach's alpha) of .87 .

Factor loadings were all above .63.

Regression analysis revealed that mental toughness significantly predicted individual $\mathrm{P}$ Company performance $\left(\mathrm{R}^{2}=.14 ; \beta=.36, p=<.01\right)$. Moreover, hierarchical regression analysis revealed that MTMTI predicted variance in performance (Block 2: $\Delta \mathrm{R}^{2}=.06, \beta=$ $.26, p=<.01$ ) over and above that accounted for by the fitness measure (Block $1: \mathrm{R}^{2}=.15, \beta$ $=.30, p=<.01)$.

\section{Discussion}

The purpose of the present series of studies was to develop and validate a measure of mentally tough behavior in a military training environment. Study 1 found good support for the structural validity of the MTMTI, while Study 2 found support for the concurrent, predictive, and test retest reliability. The predictive validity of the MTMTI was further supported in a specialized infantry sample. Moreover, the predictive validity tests demonstrated that the MTMTI predicted objective performance while controlling for another measure of mental toughness (SMTQ in Study 3) and fitness (in Study 4). Overall, the MTMTI demonstrated good psychometric properties across 4 separate samples and the predictive validity was supported in two separate samples. Consequently, these results provide some further support for Hardy et al.'s (2013) proposal that mental toughness should be assessed via observer rather than self-report ratings.

The current research is an important first step in developing a valid measure of mental toughness in a military context. Having a valid scale that stands up well to both psychometric and predictive testing allows researchers to examine mental toughness both from applied and theoretical perspectives that will help to further our understanding of mentally tough behavior. For example, the current measure will allow for further exploration of the neuropsychological underpinnings of mentally tough behavior across contexts. 
MILITARY TRAINING MENTAL TOUGHNESS INVENTORY

Namely, whether Hardy et al. (2013) counter intuitive finding that mentally tough behavior was related to high levels of punishment sensitivity and low levels of reward sensitivity in cricketers (see Gray \& McNaughton, 2000 for a review of reward and punishment sensitivity, and Hardy et al., for a description of how reward and punishment sensitivities might be related to mental toughness). It would seem prudent to examine these results across different contexts.

Based on the findings from Hardy et al. (2014), Bell et al. (2013) developed a successful multimodal intervention that was designed to impact mental toughness in elite level cricketers. Consequently, the MTMTI could potentially be used to conduct similar interventions to evaluate mental toughness in a military training environment. The intervention contained three main components; exposure to punishment conditioned stimuli, coping skills training, and was delivered in a transformational manner. Whilst the results of the intervention indicated that it was successful in developing mental toughness by the authors own admission, no attempt was made to measure the separate effects of the punishment conditioned stimuli, the transformational delivery, or the efficacy of the coping skills. Thus, no conclusions can be inferred regarding which aspects of the intervention contributed most to the observed change in mental toughness, or indeed, whether these aspects interacted to impact the observed change in mental toughness. Consequently, further research is needed to delineate more precisely the effects that punishment conditioned stimuli, transformational delivery, and coping skills has on the development of mental toughness.

Whilst the current measure has been demonstrated to perform well in the standard tests of measurement efficacy it is noted that the scale is one-dimensional, that is, all the stressors fall under one global aspect. It is suggested that it might be possible to delineate the stressors into clusters. For example, some of the stressors identified in the MTMTI may fall 
MILITARY TRAINING MENTAL TOUGHNESS INVENTORY

393

394

395

396

397

398

399

400

401

402

403

404

405

406

407

408

409

410

411

412

under physical stress (e.g., tiredness) whilst others about threats to ego (e.g., punishments).

Further investigation of this would seem warranted. For example, all of the social pressure items (e.g., "he is not getting on with other section members") were deleted at stage 1 due to inadequate fit. Indeed, the inclusion of a multidimensional aspect to the measurement of mentally tough behavior will allow for a closer examination of the construct of mental toughness. This would allow for more in-depth questions around mental toughness to be examined, such as, whether some individuals are better able to cope with certain types of stressors than other types of stressors (e.g., social stressors, threats to ego, physical stressors etc.). Furthermore, the role that underlying personality dimensions have in determining individual differences in ability to cope with different types of stressors would also be a worthwhile area of future research. However, in order to test these and other related questions one would need to develop a multidimensional measure of mentally tough behavior. A further limitation and area worthy of future research is to explore the possibility of whether the current anchors should be more reflective of behaviors rather than a Likert type scale.

To sum up the current series of studies have gone some way toward developing and validating a measure of mental toughness in a military training environment that will hopefully stimulate further theoretical and applied research in this area. 
MILITARY TRAINING MENTAL TOUGHNESS INVENTORY

References

414

415

416

417

418

419

420

421

422

423

424

425

426

427

428

429

430

431

432

433

434

435

436

437

Andersen, M. B. (2011). Who's mental, who's tough and who's both? Mutton constructs dressed as lamb. In D. F. Gucciardi and S. Gordon (Eds.), Mental toughness in sport: Developments in theory and research (pp. 69-88). Oxon: Routledge.

Bell, J., Hardy, L., \& Beattie, S. (2013). Enhancing mental toughness and performance under pressure in elite young cricketers: A 2 year longitudinal intervention. Sport, Exercise, and Performance Psychology, 2, 281-297. DOI:10.1037/a0033129

Bull, S. J., Shambrook, C. J., James, W., \& Brookes, J. E. (2005). Towards an understanding of mental toughness in elite English cricketers. Journal of Applied Sport Psychology, 17, 209-227. DOI: 10.1080/10413200591010085

Clough, P., Earle, K., \& Sewell, D. (2002). Mental toughness: The concept and its measurement. In I Cockerill (Ed.), Solutions in sport psychology (pp. 32-43). London: Thompson.

Connaughton, D., Wadey, R., Hanton, S., \& Jones, G. (2008). The development and maintenance of mental toughness: Perceptions of elite performers. Journal of Sports Sciences, 26, 83-95. DOI:10.1080/02640410701310958

Coulter, T. J., Mallett, C. J., \& Gucciardi, D. F. (2010). Understanding mental toughness in Australian soccer: Perceptions of elite performers. Journal of Sports Sciences, 28, 699-716. DOI:10.1080/02640411003734085

Crust, L., \& Azadi, K. (2010). Mental toughness and athletes' use of psychological strategies. European Journal of Sport Science, 10, 43-51. DOI: $10.1080 / 17461390903049972$

Duckworth, A. L., Peterson, C., Matthews, M. D., \& Kelly, D. R. (2007). Grit: Perseverance and passion for long term goals. Journal of Personality and Social Psychology, 92, 1087-1101. DOI: 10.1037/0022-3514.92.6.1087 
MILITARY TRAINING MENTAL TOUGHNESS INVENTORY

Gray, J. A., \& McNaughton, N. (2000). The neuropsychology of anxiety: An enquiry into the functions of the septo-hippocampal system. Oxford, UK: Oxford University Press.

Gucciardi, D. F., \& Gordon, S. (2009). Development and preliminary validation of the Cricket Mental Toughness Inventory. Journal of Sports Sciences, 27, 1293-1310. DOI: $10.1080 / 02640410903242306$

Gucciardi, D. F., Gordon, S., \& Dimmock, J. A. (2009a). Development and preliminary validation of a mental toughness inventory for Australian football. Psychology for Sport and Exercise, 10, 201-209. DOI:10.1016/j.psychsport.2008.07.011

Gucciardi, D. F., Gordon, S., \& Dimmock, J. A. (2009b). Evaluation of a mental toughness training program for Australian footballers: 1. A quantitative analysis. Journal of Applied Sport Psychology, 21, 307-323. DOI:10.1080/10413200903026066

Gucciardi, D. F., Hanton, S., \& Mallet, C. L. (2012). Progressing measurement in mental toughness: A case example of the Mental Toughens Questionnaire 48. Sport, Exercise, and Performance Psychology, 1(13), 194-214. DOI:10.1037/a0027190.

Hammermeister, J., Pickering, M., \& Lennox, A. (2011). Military applications of performance, psychology methods and techniques: An overview of practice and research. The Journal of Performance Psychology [e-journal], 3. Available through: Centre for Performance Psychology [Accessed $28^{\text {th }}$ January 2013].

Hardy, L., Arthur C.A., Jones, G., Shariff, A., Munnoch, K., Isaacs, I., Allsopp, A.J. (2010). The relationship between transformational leader behaviors, psychological, and training outcomes in elite military recruits. The Leadership Quarterly, 21, 20-32. DOI:10.1016/j.leaqua.2009.10.002.

Hardy, L., Bell, J., \& Beattie, S. (2014). A neuropsychological model of mentally tough behaviour. Journal of Personality, 8, 69-81. DOI: 10.1111/jopy.12034 
MILITARY TRAINING MENTAL TOUGHNESS INVENTORY

463 Jones, G., Hanton, S., \& Connaughton, D. (2002). What is this thing called mental

464

465

466

467

468

469

470

471

472

473

474

475

476

477

478

479

480

481

482

483

484

485

486

487

488 toughness? An investigation of elite sport performers. Journal of Applied Sport Psychology, 14, 205-218. DOI:10.1080/10413200903026066

Joreskog, K. G., \& Sorbom, D. (2006). Lisrel 8 (version 8.0). [Computer software]. Chicargo: Scientific Software International.

Kelly, D. R., Mathews, M. D., \& Bartone, P. T. (2014). Grit and hardiness as predictors of performance among West Point cadets. Military Psychology, 26, 327-342. doi.org/10.1037/mil0000050

Kobasa, S. C. (1979). Stressful life events, personality, and health: An inquiry into hardiness. Journal of Personality and Social Psychology, 37, 1-11. DOI: 10.1037/0022-3514.37.1.1

Loehr, J. E. (1986). Mental toughness training for sports: Achieving athletic excellence. Lexington, MA: Stephen Greene.

Maddi, S. R. (2006). Hardiness: The courage to grow from stresses. Journal of Positive Psychology, 1,160-168. DOI: 10.1080/17439760600619609

Maddi, S. R. (2007). Relevance of hardiness assessment and training to the military context. Military Psychology, 19, 61-70.

Maddi, S. R., Mathews, M. D., Kelly, D. R., Villareal, B., \& White, M. (2012). The role of hardiness and Grit in predicting performance and retention of USMA cadets. Military Psychology, 24,19-28. DOI: $10.1080 / 08995605.2012 .639672$

Middleton, S. C., Marsh, H. W., Martin, A. J., Richards, G. E., \& Perry, C. (2004). Developing the mental toughness inventory. Self Research CentreBiannual Conference, Berlin.

Middleton, S. C., Marsh, H. W., Martin, A. J., Richards, G. E., \& Perry, C. (2005). Developing a test for mental toughness: The mental toughness inventory. AARE Conference, Sydney.

Sheard, M., Golby, J., \& van Wersch, A. (2009). Progress toward construct validation of the 
MILITARY TRAINING MENTAL TOUGHNESS INVENTORY

489

490

491

492

493 sports mental toughness inventory (SMTQ). European Journal of Psychological Assessment, 25, 186-193. DOI 10.1027/1015-5759.25.3.186

Wilkinson, D. M., Rayson, M. P., \& Bilzon, J. L.J. (2008). A physical demands analysis of the 24-week British Army Parachute Regiment recruit training syllabus. Ergonomics, 51, 649-662. DOI: 10.1080/00140130701757367 
Running head: MILITARY TRAINING MENTAL TOUGHNESS INVENTORY

Table 1.

Standardized factor loadings, means and standard deviations for retained items.

\begin{tabular}{|c|c|c|c|c|c|c|c|c|c|c|c|}
\hline \multirow[t]{2}{*}{4} & & \multicolumn{2}{|c|}{$\begin{array}{l}\text { Study 1a } \\
(n=279)\end{array}$} & \multicolumn{2}{|c|}{$\begin{array}{l}\text { Study } 1 \mathrm{~b} \\
(n=156)\end{array}$} & \multicolumn{2}{|c|}{ Study 2 (wk 20) } & \multicolumn{2}{|c|}{$\begin{array}{l}\text { (Study } 2 \text { wk 23) } \\
\text { 104) }\end{array}$} & \multicolumn{2}{|c|}{$\begin{array}{l}\text { Study } 3 \\
(n=134)\end{array}$} \\
\hline & & FL & $\mathrm{M}(\mathrm{SD})$ & FL & $\mathrm{M}(\mathrm{SD})$ & FL & $\mathrm{M}(\mathrm{SD})$ & FL & $\mathrm{M}(\mathrm{SD})$ & FL & $\mathrm{M}(\mathrm{SD})$ \\
\hline 1 & $\begin{array}{l}\text { His recent performances } \\
\text { have been poor. }\end{array}$ & 0.72 & $4.23(1.50)$ & 0.82 & $4.08(1.52)$ & 0.64 & $4.57(1.82)$ & 0.86 & $4.95(1.40)$ & 0.63 & $4.81(1.26)$ \\
\hline 2 & $\begin{array}{l}\text { He is in pain (e.g., associated } \\
\text { with high levels of physical } \\
\text { effort). }\end{array}$ & 0.77 & $4.06(1.78)$ & 0.74 & $3.98(1.59)$ & 0.75 & $4.86(1.76)$ & 0.87 & $4.89(1.60)$ & 0.66 & $4.78(1.48)$ \\
\hline 3 & $\begin{array}{l}\text { The conditions are difficult } \\
\text { (e.g., on exercise). }\end{array}$ & 0.80 & $4.22(1.55)$ & 0.88 & $4.12(1.49)$ & 0.82 & $5.05(1.55)$ & 0.90 & $4.91(1.58)$ & 0.87 & $5.00(1.22)$ \\
\hline 4 & $\begin{array}{l}\text { He has been } \\
\text { reprimanded/punished }\end{array}$ & 0.81 & $4.06(1.68)$ & 0.75 & $4.41(1.61)$ & 0.82 & $5.11(1.56)$ & 0.83 & $4.90(1.51)$ & 0.69 & $5.06(1.19)$ \\
\hline 5 & He has not had much sleep & 0.74 & $4.04(1.51)$ & 0.82 & $3.87(1.36)$ & 0.85 & $4.95(1.50)$ & 0.85 & $4.79(1.52)$ & 0.80 & $4.78(1.24)$ \\
\hline 6 & $\begin{array}{l}\text { He is under pressure to } \\
\text { perform well (e.g., } \\
\text { assessments, test conditions) }\end{array}$ & 0.73 & $4.41(1.62)$ & 0.72 & $4.22(1.53)$ & 0.79 & $5.23(1.65)$ & 0.84 & $4.88(1.58)$ & 0.75 & $4.92(1.36)$ \\
\hline & Total Mental Toughness & & $4.17(1.30)$ & & $4.11(1.25)$ & & $4.95(1.34)$ & & $4.89(1.36)$ & & $4.89(1.01)$ \\
\hline
\end{tabular}

Note. FL is the standardized factor loading 


\section{MILITARY TRAINING MENTAL TOUGHNESS INVENTORY}

Table 2. Means, SDs, and inter-correlations between variables in studies 2 and 3 with alpha coefficients in parenthases

\begin{tabular}{|c|c|c|c|c|c|c|c|c|c|c|c|c|}
\hline & & Mean & SD & 1 & 2 & 3 & 4 & 5 & 6 & 7 & 8 & 9 \\
\hline \multicolumn{13}{|c|}{$\underline{\text { Study } 2(n=104)}$} \\
\hline 1 & Mental Toughness (wk 20) & 4.95 & 1.34 & (.90) & & & & & & & & \\
\hline 2 & Mental Toughness (wk 23) & 4.89 & 1.36 & $.72^{* *}$ & $(.94)$ & & & & & & & \\
\hline 3 & SMTQ & 2.98 & 0.40 & $.33^{* *}$ & $.43^{* *}$ & (.78) & & & & & & \\
\hline 4 & SMTQ-Confidence & 3.08 & 0.48 & $.27^{* *}$ & $.37^{* *}$ & $.83^{* *}$ & $(.66)$ & & & & & \\
\hline 5 & SMTQ-Constancy & 3.38 & 0.45 & $.31^{* *}$ & $.40^{* *}$ & $.75^{* *}$ & $.51^{* *}$ & $(.45)$ & & & & \\
\hline 6 & SMTQ-Control & 2.42 & 0.61 & $.20^{*}$ & $.24^{*}$ & $.74^{* *}$ & $.33^{* *}$ & $.40^{* *}$ & $(.62)$ & & & \\
\hline 7 & Resilience & 3.94 & 0.70 & $.32^{* *}$ & $.35^{* *}$ & $.68^{* *}$ & $.62^{* *}$ & $.52^{* *}$ & $.46^{* *}$ & $(.81)$ & & \\
\hline 8 & Self-confidence & 4.12 & 0.63 & $.25^{* *}$ & $.33^{* *}$ & $.71^{* *}$ & $.72^{* *}$ & $.52^{* *}$ & $.38^{* *}$ & $.75^{* *}$ & $(.85)$ & \\
\hline 9 & Final Course Grade & 4.05 & 1.57 & $.33^{* *}$ & $.56^{* *}$ & $.39^{* *}$ & $.33^{* *}$ & $.39^{* *}$ & $.23^{*}$ & $.33^{* *}$ & $.35^{* *}$ & \\
\hline \multicolumn{2}{|c|}{ Study $3(n=134)$} & Mean & SD & 1 & 2 & 3 & & & & & & \\
\hline 1 & Mental Toughness & 4.89 & 1.01 & (.87) & & & & & & & & \\
\hline 2 & P Company Score & 47.25 & 17.63 & $.36^{* *}$ & & & & & & & & \\
\hline 3 & Fitness Score & 0.03 & 0.74 & $.43^{* *}$ & $.42^{* *}$ & & & & & & & \\
\hline
\end{tabular}

$* * p=<.01$

$* p=<.05$ 
Running head: MILITARY TRAINING MENTAL TOUGHNESS INVENTORY

\section{Appendix A}

Military Training Mental Toughness Questionnaire - MTMTI

Please think about each recruit and how he GENERALLY performs during training. The following questions ask you to rate how often the recruit is able to maintain a high level of personal performance, even when he is faced with demanding situations during training. Please consider each scenario individually and circle the number you think is most appropriate.

Student Army Number. Weeks under your Instruction:

HE IS ABLE TO MAINTAIN A HIGH LEVEL OF PERSONAL PERFORMANCE, EVEN WHEN;

Never Sometimes

Always

1 His recent performances have been poor

$\begin{array}{lllllll}1 & 2 & 3 & 4 & 5 & 6 & 7\end{array}$

$2 \quad \mathrm{He}$ is in pain (e.g., associated with high levels of physical effort).

$\begin{array}{llllll}2 & 3 & 4 & 5 & 6 & 7\end{array}$

$\begin{array}{lllllllllll}3 & \text { The conditions are difficult (e.g., on exercise). } & 1 & 2 & 3 & 4 & 5 & 6 & 7\end{array}$

$4 \quad$ He has been reprimanded/punished

$\begin{array}{lllllll}1 & 2 & 3 & 4 & 5 & 6 & 7\end{array}$

$5 \quad$ He has not had much sleep

$\begin{array}{lllllll}1 & 2 & 3 & 4 & 5 & 6 & 7\end{array}$

$6 \quad \mathrm{He}$ is under pressure to perform well (e.g., critical assessments/being observed)

$\begin{array}{lllllll}1 & 2 & 3 & 4 & 5 & 6 & 7\end{array}$

